\title{
TrabalHo DOMÉstico, CONSUMO E INTERSECCIONALIDADE: POSSIBILIDADES DE AGÊNCIA NA TRAJETÓRIA DE UMA (EX) EMPREGADA DOMÉSTICA
}

\author{
Renata Guedes Mourão Macedo ${ }^{1}$
}

\begin{abstract}
Resumo
O artigo reflete sobre articulação de categorias sociais da diferença e interseccionalidades a partir da análise da trajetória de uma trabalhadora doméstica em processo de transição para a profissão de técnica de enfermagem. Argumento que, na trajetória analisada, a qualificação profissional e a possibilidade de consumo de alguns bens antes acessíveis apenas ao universo das classes média e alta tiveram destaque na busca por agência, conquistas então facilitadas por um contexto socioeconômico favorável. Por meio da perspectiva antropológica, busca-se contribuir para o debate sobre articulação de categorias da diferença como gênero, classe e raça, enfocando algumas possibilidades de agência em contextos marcados por desigualdades.
\end{abstract}

Palavras-chave: Interseccionalidades. Emprego doméstico. Consumo. Agência.

1 Pesquisadora do Núcleo de Estudos dos Marcadores Sociais da Diferença (Numas/USP) e doutoranda em Antropologia Social pela Universidade de São Paulo (USP), Brasil. E-mail: renatagmourao@hotmail.com 


\title{
DOMESTIC WORK, CONSUMPTION AND INTERSECTIONALITY: AGENCY POSSIBILITIES IN THE TRAJECTORY OF A (FORMER) DOMESTIC WORKER
}

\begin{abstract}
The paper reflects on the articulation of social categories of difference and intersectionalities from the analysis of a domestic worker trajectory, who is in transition to the profession of nursing assistant. I argue that, in the analyzed trajectory, the professional qualification and the possibility to consume some goods, before accessible only to middle and upper classes, were prominent in the search for agency, achievements facilitated by a favorable socio-economic context. Through an anthropological perspective, the purpose of the paper is to contribute to the debate on the articulation of categories such as gender, class and race, focusing on the agency possibilities in contexts marked by inequalities.
\end{abstract}

Key-words: Intersectionalities. Domestic work. Consumption. Agency.

\section{INTRODUÇão}

Trabalhar como empregada doméstica no Brasil implica em 1 movimentar-se entre uma série de categorias da diferença que remetem a uma longa trajetória de desigualdades. Nesse sentido, marcações de gênero, classe e raça articulam-se, posicionando essas trabalhadoras na base das hierarquias profissionais. Contudo, conforme pontua Anne McClintock ao propor uma agenda de pesquisa com foco na articulação de tais categorias da diferença, trata-se de compreender as "negociações de poder em circunstâncias de grandes limitações", explorando a "tensão estratégica entre limitações sociais e atuação social" (MCCLINTOCK, 2010, p. 211).

Neste artigo, reconstituo a trajetória de Ana que, entre 2010 e 2012, então com 27 anos, trabalhava como empregada doméstica na cidade de São Paulo e em 2013 conseguiu mudar de profissão, tornando-se técnica de enfermagem² ${ }^{2}$ O objetivo é compreender o

As entrevistas e conversas aqui apresentadas são parte de pesquisa de mestrado em

Antropologia Social, realizada entre 2010 e 2013, sob a perspectiva do método etnográfico, 
modo como Ana atuou no período analisado, em consonância com um contexto social mais favorável, marcado pelo crescimento da "nova classe trabalhadora" (SOUZA, 2010). Tal fenômeno, que na mídia ficou conhecido pela linguagem de mercado como ascensão da "classe $C^{\prime}$, também esteve no foco de uma série de reportagens e representações midiáticas no período analisado, muitas delas protagonizadas por empregadas domésticas (MACEDO, 2015). Nesse processo, o aumento das possibilidades de consumo e de crédito, além do maior acesso a oportunidades de qualificação profissional, tiveram destaque, trazendo novas possibilidades de agência para os atores envolvidos.

Para tanto, tomo como referência teórico-metodológica a perspectiva da interseccionalidade ou articulação de categorias, tendo como ponto de partida as conceitualizações "que integram, numa unidade indissociável, sexo, raça e classe" (HIRATA, 2014, p. 62). Conforme reconstitui Adriana Piscitelli (2008), em meados da década de 1990 emergem no debate internacional análises que enfatizam a multiplicidade de diferenciações que, articulando-se a gênero, permeiam o social. Surgem assim as noções de interseccionalidades e/ou articulação, que ganham destaque nos debates feministas especialmente por meio das obras de Avtar Brah (2006), Anne McClintock (2010) e Kimberlé Crenshaw (2002). Nos anos 2000, tais noções já estavam bastante difundidas, espraiando-se para outros contextos, ainda que com matizes teóricos diferenciados. Segundo Piscitelli, a principal aposta desta perspectiva é "oferecer ferramentas analíticas para apreender a articulação de múltiplas diferenças e desigualdades"; apresentam, contudo, divergências em relação às margens de agência concedidas aos sujeitos (PISTICELLI, 2008, p. $266)^{3}$.

que contou com a participação de 28 mulheres que trabalhavam como empregadas domésticas na cidade de São Paulo (SP).

3 O debate acerca da constituição dos estudos sobre interseccionalidades e articulação de categorias da diferença, com reflexões sobre as distintas incorporações de tais perspectivas 
Entre as autoras que investem na ideia de articulação de categorias da diferença, destaca-se a obra de Anne McClintock (2010). Ao analisar a constituição do império britânico e o embate colonial, McClintock propõe uma perspectiva teórico-metodológica que aposta na articulação de categorias analíticas como gênero, classe e raça, de modo que se constituem em "relações íntimas, recíprocas e contraditórias" (MCCLINTOCK, 2010, p. 20). Não se trata, contudo, de utilizar tais categorias de modo universal. Pelo contrário, o esforço da autora é mostrar o modo situado como tais classificações operam em cada contexto de poder.

Neste sentido, o emprego doméstico no Brasil, sendo uma profissão historicamente feminina, racializada, e que recruta profissionais de classes trabalhadoras, torna-se um lugar estratégico para se pensar na articulação de diferentes marcadores sociais da diferença. Dentro desse contexto mais amplo, focar em trajetórias específicas, por meio do olhar etnográfico, nos permite ver de modo privilegiado a dialética entre agência e estrutura social (ORTNER, 2006a), refletindo sobre negociações e possibilidades de atuação, ainda que limitadas, em contextos históricos e sociais específicos.

\section{ESPAÇO DOMÉSTICO E TRABALHO: BREVES CONSIDERAÇÕES HISTÓRICAS}

A ideia do espaço "doméstico", segundo Anne McClintock (2010, p. 63), não pode ser aplicada universalmente a qualquer casa ou domicílio, exigindo para sua compreensão uma genealogia. Etimologicamente, o verbo domesticar tem origem similar ao verbo dominar, ambos derivando de dominus, senhor do domus, o lar. Ao analisar a Inglaterra vitoriana, a autora destaca como nesse espaço se desenvolveram inflexões centrais para a constituição da sociedade burguesa moderna, como a separação entre público e privado,

nas ciências sociais brasileiras, também podem ser conferidos em Moutinho (2014) e Hirata

(2014), entre outros trabalhos. 
masculino e feminino, trabalho e lazer, trabalho produtivo e não produtivo, trabalho servile assalariado, assim como o desenvolvimento correlato das noções de raça e classe. Naquele momento, ocorria o que a autora denominou como o "culto da domesticidade": um processo de subestimação do trabalho feminino, no qual todo sinal de seu esforço tinha que ser ocultado. Tendo seu ápice na transição da economia feudal para o capitalismo industrial, esse processo teve como resultado, por um lado, a invenção histórica do lazer e, por outro, a da "empregada doméstica invisível" (MCCLINTOCK, 2010). Assim, no discurso dominante sobre a época, enquanto a mulher vitoriana era descrita como ociosa e dedicada exclusivamente ao lazer e aos romances, o trabalho doméstico ficava restrito às criadas, mantidas grande parte do tempo fora de vista, reclusas nas áreas de serviço. Essas trabalhadoras, ao transgredir as fronteiras vitorianas entre o público e o privado, o trabalho e o lazer, o trabalho pago e o não pago, eram estigmatizadas, racializadas e "fetichizadas" como perigosamente ambíguas (MCCLINTOCK, 2010, p. 84).

No Brasil, desde o início da colonização portuguesa o emprego doméstico esteve presente. Conforme análise de Gilberto Freyre (2006), os escravos domésticos tiveram papel destacado na vida colonial; para além da intimidade por vezes estabelecida no interior Casa Grande, violência e sadismo constituíam-se como aspectos indissociáveis das relações que envolviam brancos e negros ${ }^{4}$. No final do século XIX, após a abolição da escravidão, o trabalho doméstico tornou-se a maior fonte de trabalho feminino no Brasil. Naquele momento, ainda era compreendido como uma "ajuda" em troca de casa e comida para as trabalhadoras pobres, brancas e não brancas (MELO, 1998, p.1). Com os processos de industrialização e de urbanização, associados à expansão da classe média, a atividade foi gradualmente transformando-se em

4 Sobre a articulação entre raça, gênero, nação e emprego doméstico no Brasil no período colonial e posteriormente, ver Lima e Rezende (2004). 
trabalho remunerado. Entretanto, ao longo da primeira metade do século XX, essa ideia de "ajuda" ainda se mantinha em muitas famílias (MELO, 1998).

Nas décadas de 1960 e 1970, a profissão ainda era fortemente estigmatizada e desvalorizada. Em 1970, embora as empregadas domésticas representassem mais de um quarto da força de trabalho feminina (BRUSCHINI \& LOMBARDI, 2000), para muitas famílias de classes média e alta essas trabalhadoras ainda eram vistas como "criadas" que tinham que as servir, mesmo que tivessem que abrir mão de suas vidas particulares. A profissão era marcada por salários baixíssimos, jornadas de trabalhos extensas e o maior índice de informalidade do mercado de trabalho feminino (SAFFIOTI, 1998). Foi também na década de 1970 que o trabalho doméstico foi reconhecido como profissão. Originalmente excluído da Consolidação das Leis do Trabalho (CLT) de 1943, foi apenas por meio da Lei no 5.859, de 1972, que a atividade passou a ser definida e regulamentada (IPEA, 2011).

$\mathrm{Na}$ década seguinte, com a promulgação da Constituição Federal de 1988, embora pela primeira vez os trabalhadores domésticos garantissem direitos como décimo terceiro, salário mínimo e licençamaternidade, o texto excluía esse grupo profissional dos demais direitos assegurados aos trabalhadores brasileiros, como fundo de garantia por tempo de serviço (FGTS), seguro-desemprego e regulamentação da jornada de trabalho.

Com o movimento de ingresso de mulheres de classes média e alta no mercado de trabalho intensificado durante a década de 1970, houve um aumento significativo no número de empregadas domésticas no país. Assim, seu contingente teve um aumento de mais de 200\% entre as décadas de 1970 e 1990 (BRUSCHINI \& LOMBARDI, 2000). Nesse cenário, constatava-se, a partir de 1990, que a entrada das mulheres de classes média e alta no mercado de trabalho viabilizava- 
se, em parte, graças à transferência dos serviços do lar para as empregadas domésticas.

CONTEXTO RECENTE: TRANSFORMaÇÕes E PERMANÊNCIAS NO EMPREgo DOMÉSTICO E NA “NOVA CLASSE TRABALHADORA"

Nas últimas décadas, os números relacionados ao emprego doméstico no Brasil permaneceram muito expressivos. Em 1995, cerca de 5 milhões de mulheres eram empregadas domésticas, representando $19 \%$ da população economicamente ativa feminina, de acordo com dados da Pnad (MELO,1998). Em 2009, foram contabilizados cerca de 7 milhões de empregados domésticos. Desses, 6,7 milhões eram mulheres, representando $17 \%$ da população econômica ativa feminina, e mais de 60\% eram negras (IPEA, 2011, p.4-5).

Em 2011, pela primeira vez na história nacional, houve uma diminuição no número absoluto de empregados domésticos; segundo a PNAD 2011, foram contabilizados 6,6 milhões de trabalhadores no serviço doméstico (sendo 6,1 milhões de mulheres, o que representava 15,6\% da PEA feminina) (DIEESE, 2013). Já os dados da PNAD 2013 registraram 6,4 milhões de empregados, mantendo uma leve tendência de queda (AVELINO, 2015). Também na região metropolitana de São Paulo, a proporção das empregadas domésticas no total das ocupações femininas seguia diminuindo, correspondendo a $13,7 \%$ (versus $70,9 \%$ no setor de serviços), o menor número da série da pesquisa (SEADE, 2015). Segundo o relatório, na última década teria ocorrido uma maior diversificação da oferta de trabalho feminino, levando as mulheres a buscarem "atividades de maior prestígio e em setores mais estruturados, permanecendo nos serviços domésticos, principalmente, aquelas nas faixas etárias mais elevadas e com menor escolaridade" (SEADE, 2015, p. 13). Ainda assim, conforme apontam Brites e Picanço 
(2014, p. 136), o emprego doméstico no Brasil segue sendo "um grande absorvedor de mão-de-obra", especialmente feminina e negra ${ }^{5}$.

Após anos de lutas feministas e sindicais, em abril de 2013 foi aprovada a "PEC das Domésticas" (Emenda Constitucional no 72/2013), que equiparou os direitos dos empregados domésticos aos demais trabalhadores urbanos e rurais, conforme previsto no artigo $7^{\circ}$ da Constituição Federal de 1988. A PEC estendeu a todos os trabalhadores domésticos o limite de 44 horas semanais e 8 horas diárias, além da obrigatoriedade do pagamento de horas extras, adicional noturno e Fundo de Garantia por Tempo de Serviço (FGTS).

Embora seja difícil analisar o impacto dessas mudanças, já que são recentes, elas refletiram a conjuntura socioeconômica do país e indicaram algumas transformações no período analisado. O cenário de redução da miséria, ativação do mercado interno, expansão do ensino médio, diminuição do desemprego, entre outros pontos resultantes do "lulismo"6, propiciaram um contexto mais favorável para transformações nas classes populares do que nas décadas anteriores, apesar da lentidão do processo de redução das desigualdades (SINGER, 2012). Destacou-se nesse processo a expansão da chamada "nova classe trabalhadora"7 (SOUZA, 2010), mudança que incidiu na

5 Contudo, alguns dados referentes ao período subsequente apontam para um novo crescimento do setor de serviços domésticos. Segundo reportagem do jornal Folha de São Paulo, o número de empregados domésticos no país teria passado de 6,1 milhões em 2014 para 6,3 milhões em 2015, revertendo a tendência de queda diante da crise econômica iniciada no período, levando trabalhadores a voltarem para o setor (VERSIANI, 2015).

6 Segundo Singer (2012), o "lulismo" refere-se ao processo de mudanças ocorridas no Brasil a partir de 2003, por meio de um "reformismo fraco". Entre o primeiro e o segundo mandato de Luiz Inácio Lula da Silva, o Lula, deu-se a implementação progressiva do modelo "diminuição da pobreza com manutenção da ordem" (2012, p.13). Entre outras resultantes desse programa, foi possível "combater a pobreza, sobretudo onde ela é mais excruciante tanto social quanto regionalmente, por meio da ativação do mercado interno, melhorando o padrão de consumo da metade mais pobre da sociedade, que se concentra no Norte e Nordeste do país, sem confrontar os interesses de capital" (SINGER, 2012, p. 16).

7 Conforme define Souza (2010, p. 26), a "nova classe trabalhadora" brasileira se situa "entre a ralé e as classes média e alta". Essa classe se inclui no sistema econômico "como produtora de bens e serviços valorizados ou como consumidora crescente de bens duráveis e serviços" que 
vida das profissionais envolvidas na pesquisa. Segundo Souza (2010, p. 50-52), no processo de emergência dessa nova classe, os chamados "batalhadores" realizaram um extraordinário esforço para conciliar trabalho duro com o retorno aos estudos, permitindo descolar-se do "presente eterno" e elaborar planos para o futuro, criando assim "narrativas de sucesso relativo para suas trajetórias pessoais" .

Apesar das polêmicas em torno do debate a respeito da entrada dessa parcela da população em uma "nova classe média" - termo amplamente criticado por Souza (2010) - o aumento do poder de consumo das bases da pirâmide econômica brasileira foi inegável no período. Nesse sentido, a posse de bens de consumo como microcomputadores e celulares, entre outros, aumentaram substancialmente entre 2002 e 2009, conforme demonstram Scalon e Salata (2012). Também Scalco e Pinheiro-Machado (2010) apontam para a visibilidade que o "consumo popular" ganhara no período, relacionando o fenômeno ao aumento das linhas de crédito e maior distribuição de renda. Assim, paralelamente ao debate travado em torno dessas mudanças, foi inegável o interesse renovado do mercado e da mídia nesse nicho econômico (ALMEIDA, 2015). Entre reportagens e representações midiáticas que tratavam do tema da chamada "expansão da classe $C^{\prime}$, empregadas domésticas tiveram protagonismo em diversas delas. Entre outras representações, destacou-se a telenovela Cheias de Charme (Globo, 2012, 19h30), na qual três empregadas domésticas - agora alçadas à posição de protagonistas - encenavam trajetórias de ascensão social, conquistando disputas trabalhistas e bens de consumo antes inacessíveis (MACEDO, 2013). Apesar das transformações, mantinha-se alguns estereótipos sobre as classes trabalhadoras brasileiras, além da visão de que o consumo é

antes eram privilégio dos mais ricos. Também se define por um estilo de vida próprio e uma visão de mundo "prática". Resulta de mudanças sociais ocorridas no capitalismo brasileiro e mundial especialmente a partir dos anos 2000. 
uma esfera feminina, devendo ser especialmente direcionado para as mulheres (ALMEIDA, 2007).

Reconstituo aqui esse breve panorama para esboçar o pano de fundo no qual sobreponho as trajetórias de trabalhadoras domésticas analisadas no período entre 2010 e 2013, Ana entre elas, enfocando sua busca por melhorias trabalhistas, educacionais e o maior acesso a bens de consumo. Utilizando os termos de Gilberto Velho, o objetivo é perceber algumas transformações no "campo de possibilidades" para então compreender a elaboração dos "projetos individuais " que aí operam (VELHO, 2013, p.65). Pretende-se, assim, apreender de modo localizado a sutileza das possibilidades de agência em tais contextos, sem perder de vista a produção e reprodução de múltiplas desigualdades em interseção. Conforme sugere Sherry Ortner (2006b), trata-se de levar em consideração contextos específicos de desigualdades enfocando, simultaneamente, "atos de agência" compreendidos como ações intencionais dos sujeitos que incluem "enredos, planos e esquemas altamente conscientes; metas, objetivos e ideais um pouco mais nebulosos; e, finalmente, desejos, vontades e necessidades que podem variar de profundamente encobertos a bastante conscientes" (ORTNER, 2006b, p. 52).

\section{A trajetória de ana: atuações possíveis}

No início da pesquisa, quando conheci Ana, em 2010, ela trabalhava como empregada doméstica em dois apartamentos em um mesmo edifício na região nobre da zona sul de São Paulo. Então com 27 anos, autodeclarada negra, ela também morava na zona sul, mas na periferia da capital, em bairro próximo à cidade de Diadema. Durante a pesquisa etnográfica, além de diversas conversas espontâneas, também realizei duas entrevistas semi-estruturadas em sua casa. A seguir, a partir desses diferentes materiais, reconstituo alguns 
momentos de sua trajetória. Foi desde modo que ela iniciou nossa primeira entrevista:

Lá em Minas [estado em que nasci] eu é que tinha que pegar lenha, eu é que tinha que limpar a casa... Depois eu te mostro a fita do [apresentador de televisão] Gugu, eu fui no programa dele contar a minha história. Eu sofri muito... Eu tinha 14 anos quando eu vim pra São Paulo com a minha tia. Mas também pastei na mão dela aqui. Não foi fácil não. Eu só aprendi a ler na quinta série, quando eu já estava aqui. Eu vim aprender a ler aqui, eu não sabia ler, porque lá eu só trabalhava, minha avó não deixava eu estudar. Ela dizia que se eu ia estudar eu ia "arrumar bucho". Esse povo... achava que eu iria para a escola para "caçar macho". Eu que quis estudar, com 14 anos fui atrás de vaga, pedi para um vizinho assinar para mim, porque antes eu não tive essa oportunidade.

A trajetória de Ana, de acordo com sua própria reconstituição, inicia-se assim marcada por uma série de assimetrias de poder: a infância pobre, o trabalho doméstico exaustivo feito em prol de familiares, o enfrentamento de desigualdades de gênero, classe e cor, a precariedade dos estudos iniciais, a experiência da migração para São Paulo. Tais marcações foram recorrentes em outras trajetórias de trabalhadoras domésticas por mim pesquisadas no período e são também frequentes em outras pesquisas sobre emprego doméstico (KOFES, 2001;BRANDT, 2003; BRITES, 2007; LIMA \& REZENDE, 2004). Contudo, no caso de Ana, tais marcas não eram reconstituídas apenas em um processo de compreensão das desigualdades enfrentadas, mas também como uma comprovação da sua capacidade para lidar com adversidades. Conforme as noções sugeridas por Sherry Ortner (2006b, p. 54), mais do que "práticas de rotina", Ana reconstituía sua trajetória passada e formulava suas expectativas de futuro a partir de "atos de agência", buscando evidenciar sua intencionalidade diante dos fatos, apesar de seu lugar marcado como mulher negra e pobre, 
então empregada doméstica. Ainda que "enredada em relações de poder, de desigualdade, e assim por diante" (ORTNER, 2006b, p. 47), Ana direcionava suas ações, "cognitiva e emocionalmente, para algum propósito" (ORTNER, 2006b, p. 52).

Assim, em 2010, quando iniciei a pesquisa, Ana considerava com orgulho que conseguira "sobreviver" na metrópole e ressaltava suas conquistas. Já em São Paulo, ainda adolescente, retornou à escola pública, concluindo o ensino médio. Nesse período, casou-se com um homem, também negro, com quem depois teve um filho, então com 5 anos no período inicial da pesquisa. Ela e o esposo trabalhavam no mesmo edifício: ele como zelador; ela como empregada doméstica em dois apartamentos (no primeiro, como mensalista quatro dias na semana, no segundo como diarista um dia na semana).

Apesar de, na época, falar com orgulho das atividades profissionais que realizava, quando questionada sobre emprego doméstico, uma série de contradições vinham à tona: por um lado, "amava" seus patrões, vistos como generosos e educados; por outro, sonhava em superar essa profissão, considerada desvalorizada e permeada por estigmas. Essa visão ambígua da profissão foi recorrente também entre outras interlocutoras da pesquisa e já fora mencionada em outras análises sobre trabalho doméstico remunerado, como na de Maria Elisa Brandt (2003); apesar de identificar melhorias nas condições socioeconômicas e de trabalho em relação às décadas de 1970 e 1980, Brandt concluía que, por um lado, as trabalhadoras valorizavam "o bom salário em comparação ao de parentes e conhecidas", por outro lado, descreviam "atitudes e sentimentos que denotam a vergonha em ser doméstica, o estigma enraizado" (BRANDT, 2003, p. 135).

Nessa posição que Ana então ocupava, a questão do consumo se revelou um eixo importante de atuação. Para ela, assim como para outras interlocutoras da pesquisa, o que consumir, como, quando, onde, de qual marca, eram dilemas recorrentes, revelando 
a polissemia que atos de consumo podem apresentar em diferentes contextos (DOUGLAS \& ISHERWOOD, 2004). Seja pela adesão ao consumo de bens mais caros e valorizados, seja pelo controle financeiro mais estrito, tais questões permeavam muitas das ações e decisões no cotidiano dessas trabalhadoras. Mas nesse âmbito, diferente de outros grupos profissionais, as trabalhadoras domésticas apresentam especificidades em função da convivência com patroas e patrões de níveis econômicos mais altos. Trata-se do fenômeno recorrente da transferência de bens materiais, novos e usados, dos patrões para as empregadas, além de uma circularidade desses bens nas redes de sociabilidade das trabalhadoras. Outro ponto específico dessa relação refere-se à incorporação, por parte das empregadas, de objetos e estilos de vida adotados por seus empregadores. Conforme sintetizara Marlucia, outra interlocutora dessa pesquisa, "um dos maiores problemas de se trabalhar em casa de família é se acostumar com o que é bom". Contudo, conforme análise de Carla Barros (2007), ao refletir sobre como o consumo pode ser influenciado na relação entre patroas e empregadas, constatou que havia circulação e troca em relação a hábitos alimentares, cuidados com a casa e produtos de limpeza. Já na influência em matéria de produtos de beleza, por exemplo, tendia a ser unilateral, circulando da patroa para a empregada.

No caso de Ana, na relação com seus patrões, aproximações e afastamentos nas hierarquias do espaço social eram especialmente dimensionados por bens de consumo, os quais também eram indicativos da posição de classe alta de seus empregadores:

Pesquisadora: da outra vez você tinha me contado que seus empregadores te dão muita coisa, né?

Ana: Ish minha filha, quase tudo o que tem na minha casa a gente ganhou dos patrões. Essa televisão, esse rack, esse sofá. Aquele guarda-roupa do meu quarto, o guarda-roupa do quarto do meu filho...

P: Seus patrões trocam muito de guarda-roupa? 
A: Final de ano eles trocam. Eles trocam e dão, é celular... esse celular mesmo minha patroa me deu agora [um smartphone]. Eles vão sempre para os Estados Unidos, trazem muita coisa, é tênis, é roupa...

$P$ : Eles são bem ricos?

A: [Ela fala mais baixo] Meu patrão é rico sim, ele é engenheiro. Acho que ele deve ganhar mais de 50 mil reais... Eles moram na cobertura!

Sendo o consumo um marcador privilegiado de posições sociais e gerador de distinções (BOURDIEU, 2007), Ana via na profissão de engenheiro, no tipo de residência (cobertura) e nos bens consumidos (muitos deles comprados nos Estados Unidos) indícios das posições diferenciais de classe social ocupadas por ela e os patrões, portanto, indicativa de grande desigualdade social.

Contudo, além de reforços às desigualdades, o consumo também se articulava como ação que a aproximava de seus empregadores, matizando tais diferenciações. Constantemente, ao referir-se as possibilidades de consumo de seus patrões, Ana também ressaltava as suas próprias, entre elas a recente aquisição de um carro zero (modelo Renault Sandero, de cor vermelha), o qual utilizava apenas aos finais de semana para ir ao salão de cabelereiro, ao supermercado e a festas. Também ressaltava que, embora morasse "na favela", sua casa era bastante bem equipada e bonita, com destaque para a pintura externa lilás. Tinha acesso regular à internet e, aos finais de semana, assistia televisão à cabo, com preferência para seriados norte-americanos. Assim, afastando-se da persistente visão que associa o consumo popular à "razão prática", a qual estaria pautada exclusivamente pela "utilidade, necessidade e sobrevivência" (SCALCO \& PINHEIRO-MACHADO, 2010, p.322), Ana reivindicava a polissemia de sentidos que atos de consumo apresentavam em sua trajetória, constituindo também aí um lugar de atuação. Conforme apontam Scalco e Pinheiro-Machado (2010, p.325), ao enfatizar as 
dimensões simbólicas do consumo popular, este também "deve ser tratado como uma forma de agência, empoderamento e cidadania". De modo geral, o maior acesso a uma série de bens de consumo, materiais e culturais, matizavam parte das desigualdades sociais, trazendo para Ana uma maior sensação de proximidade com os patrões, apesar das marcações diferenciais de classe, raça, profissão e origem:

Eu não tenho mais esse negócio de pobre ou rico não, para mim todo mundo é igual. Mas eu também não deixo ninguém me humilhar não, por mais que seja do alto ou do baixo. Todo mundo tem que se respeitar igual.

Ana vivia nesse momento uma situação contraditória em relação ao emprego doméstico, descrita por Brites e Picanço (2014): se, por um lado, o aumento de expectativa em relação ao consumo e ao estilo de vida reforçava a desvalorização e o estigma do trabalho doméstico como atividade remunerada, por outro lado, era justamente essa profissão que lhe permitia manter esse novo estilo de vida, em função da "valorização real da remuneração do trabalho doméstico nos grandes centros urbanos e bairros de classe média e alta" (BRITES \& PICANÇO, 2014, p. 138).

Ainda assim, Ana tinha claro que não era apenas a posse do carro novo, entre outros bens adquiridos recentemente, que seriam capazes de movimentá-la no espaço social. Então, em busca do sonho de trocar de profissão, Ana cursava um curso técnico de enfermagem no período noturno, após o serviço.

Quando encontrei novamente Ana em março de 2012, com o curso já mais adiantado, ela enfrentava um grande dilema profissional. Sempre que questionada sobre seu trabalho, buscava enfatizar que gostava de ser empregada doméstica, que recebia um bom salário e que mantinha boa relação com as patroas e patrões. O problema era, segundo Ana, o preconceito: 
Outra colega minha [do curso técnico em enfermagem] esses dias estava falando que estava com a mão inchada, reclamando que era de limpar a casa dela. Aí eu disse que eu limpava a casa dos patrões e depois a minha. E ela disse: "ai, não sei como você aguenta, eu é que não prestava pra limpar banheiro dos outros, é uma humilhação". Eu falei: "humilhação é você roubar, ser presa e ficar pedindo pra parente ir te levar as coisas. Isso é que é humilhação. A minha mão também tá com calo, mas eu pelo menos tenho comida, tenho minha casa, tenho saúde, tenho até um carrinho zero agora!" Isso é o que interessa, não é?" E ela falando, sabe assim te rebaixando? Parece que tem gente que gosta de pisar, né? E eu falei: "se eu não trabalhasse bem, eu não estava empregada, registrada. Na outra casa ela me paga $R \$ 100$ por dia, e a outra paga muito bem o mês, e você, quanto ganha?".

Ao referir-se com desprezo ao "banheiro dos outros", a colega de Ana escancarava alguns dos estigmas associados às atividades enfrentadas por uma empregada doméstica. Ana combatia tal argumento realçando a sua valorização enquanto profissional honesta, naquele momento mais bem remunerada do que a amiga da área da saúde que a havia interpelado. Ainda assim, Ana revelava que, na verdade, vivia um grande dilema. Questionada pela decisão de estudar enfermagem, afirmava que gostava muito de "ajudar os outros" e ser técnica de enfermagem era, afinal, uma profissão "mais bonita". Porém, acreditava que ainda não era o momento de deixar "a sua" patroa, então grávida e precisando muito de seu auxílio para cuidar do outro filho ainda pequeno.

Eu também não vou sair assim do meu serviço e deixar minha patroa na mão, né? Coitada! Quando eu terminar o curso... se bem que eu queria sair já, mas como é que eu saio? Eu tenho pena dela! [...] Ela me pede 'fica mais comigo, vai fazendo os seus cursos, depois você vai'. 
Ana revelava assim viver uma situação típica entre patroas e empregadas domésticas, descrita por Brites (2007) como "ambiguidade afetiva"; nessas relações, a distância socialé simultaneamente permeada por uma carga forte de afetividade. Além disso, essa patroa também estava lhe auxiliando no pagamento do curso técnico, cobrindo parte dos gastos, estreitando ainda mais a relação trabalhista e pessoal. Outro desestímulo naquele momento para trocar de profissão era que, ao procurar trabalho em hospitais ou em homecare, percebeu que para se introduzir na carreira, ganharia menos do que então recebia como empregada doméstica. E a natureza dessa atividade também era problemática, ainda associada ao cuidado e ao doméstico, o que leva à persistente feminização da enfermagem (LOPES \& LEAL, 2005). Em entrevista, recordando outro diálogo com uma colega do curso, Ana contou:

Mas você estava falando de preconceito, né? Até na área de saúde tem. Você acredita que semana passada eu estava perguntando para as colegas que já estão trabalhando sobre o salário, como é que funciona, aí uma colega falou que trabalhava de homecare. Aí a outra falou: "Deus me livre limpar bunda de velho!" Você acredita? Porque eu penso assim, essa área você não pode escolher. Eu peguei e falei: "nossa, tudo vocês têm preconceito". E essa falou assim: "Eu vou estudar tanto pra me humilhar? Eu não vou limpar bunda dos outros". Só que o professor ouviu e falou "minha filha, o que é que você está fazendo aqui? Se você está trabalhando num hospital grande você acha que a enfermeira vai perguntar qual o paciente você vai pegar? Você pode trabalhar no [hospital Albert] Einstein, mas se tiver qualquer paciente lá, você pode estar ganhando 5 mil reais, você vai ter que limpar". Tá na área pra que?

Essa reflexão revela alguns dos dilemas então vividos por Ana: trabalhando como empregada doméstica ela tinha melhor remuneração do que uma técnica de enfermagem em início de carreira. A necessidade de lidar com a sujeira, com "fluídos poluentes", nos 
termos de Mary Douglas (1976) existia nas duas profissões. Porém, lhe parecia mais bonito andar de branco e contar para os outros que trabalharia na área da saúde do que revelar que era empregada doméstica, profissão historicamente mais associada às desigualdades de gênero, raça e classe em intersecção. Enquanto essa mudança não ocorria, Ana também seguia apostando na construção de seu estilo pessoal. Nessa época, realizou um alongamento dos cabelos, procedimento considerado caro, mas que, segundo ela, teria valido a pena. Acompanhando-a um dia à cabelereira em sua vizinhança, antes de ir a uma festa, Ana então expressava orgulho de sua negritude, espelhando-se em uma cantora pop estadunidense: "quero os cachos da Beyoncé porque preciso arrasar", solicitava à amiga. Ainda que distante do ideal do "cabelo natural como símbolo de afirmação de identidade" conforme defendido por alguns movimentos negros (FIGUEIREDO, 2002, p.6), Ana identificava nessa cantora uma mulher negra e empoderada, colaborando para "o fortalecimento de sua autoestima negra" (FIGUEIREDO, 2002, p. 13), construindo assim mais um lugar de atuação.

Em 2013, ao reencontrar Ana já após o término da pesquisa de mestrado, ela contava orgulhosa que tinha conseguido concluir o curso e estava empregada como técnica de enfermagem em um hospital de Diadema (SP). Apesar de algumas dificuldades e hierarquias também encontradas no novo serviço, mais uma vez orgulhava-se de suas conquistas - ela finalmente conseguira mudar de profissão. O marido seguia trabalhando de zelador, seu filho estudava em uma escola particular próxima ao seu bairro e ela agora contratava uma diarista uma vez por semana para auxiliá-la nas tarefas domésticas de sua própria casa.

\section{CONSIDERações FinaIS}


Conforme discutido neste artigo, o emprego doméstico ainda é uma atividade importante entre as mulheres de baixa renda no Brasil, empregando milhões de trabalhadoras. Acompanhando brevemente a história dessa profissão, nota-se quehouve transformaçõesimportantes, resultando em maior acesso a direitos trabalhistas, rendimentos e bens de consumo. No entanto, a atividade permanece marcada por índices altos de informalidade, baixos salários e cortes expressivos de gênero, classe e raça, posicionando-se nos degraus mais baixos das hierarquias profissionais. Conforme sintetiza Jurema Brites, ainda se trata de "atividade altamente feminilizada e fruto do entrecruzamento de desigualdades" (BRITES, 2013, p. 428). Em paralelo, desigualdades sociais persistem também no meio social em que essas trabalhadoras são recrutadas, especialmente no que se refere ao acesso à educação, moradia, equipamentos culturais e sistema de saúde. Tais deficiências no acesso a direitos sociais são visíveis na pesquisa por mim realizada em São Paulo e devem ser ainda mais expressivas em outras regiões do país. No entanto, se é possível inferir que o emprego doméstico se constitui por meio de desigualdades articuladas (MCCLINTOCK, 2010), isso não quer dizer que também não se constitua como lócus para negociações e resistências (KOFES, 2001).

Com o recente processo de expansão da chamada "nova classe trabalhadora" (SOUZA, 2010), o olhar para a trajetória de trabalhadoras domésticas se revelou um eixo importante para se compreender os dilemas e desafios desse fenômeno social mais amplo. Nesse sentido, a expansão do consumo e a possibilidade de acesso a bens materiais e culturais antes mais restritos às classes média e alta se revelaram eixos importantes, na medida em que contribuíram para "transmutar exclusão em inclusão" (SCALCO \& PINHEIRO-MACHADO, 2010, p. 325). Também a conciliação do trabalho com o retorno aos estudos embora efetivado apenas por uma minoria das mulheres participantes 
dessa pesquisa ${ }^{8}$ - teve papel de destaque na busca por agência em algumas trajetórias, especialmente entre as mulheres mais jovens.

No caso específico de Ana, conforme vimos, partindo de um lugar social marcado pela pobreza, pela migração, pelo estigma do trabalho como empregada doméstica, ela agiu de modo a aproveitar as possibilidades de atuação que lhe surgiram. No período analisado, pôde adquirir alguns bens de consumo antes apenas acessíveis ao universo dos patrões (com destaque para o carro zero) e qualificarse profissionalmente, tornando-se auxiliar de enfermagem em um hospital.

Não se trata de superestimar as conquistas de Ana - afinal, sua posição atual como técnica de enfermagem segue sendo imbricada por distintas assimetrias de poder ligadas a gênero e classe, entre outros marcadores. Tampouco se trata de mobilidade social efetiva - ela segue vivendo no mesmo bairro periférico e pobre, ainda não cursou ensino superior (visto como um sonho), recebe rendimentos próximos ao que tinha antes, etc - contudo, sua própria percepção era de grandes conquistas. Conforme sugestão teórico-metodológica de McClintock (2010, p. 211), trata-se justamente de compreender "que tipo de atuação é possível em situações de desigualdade social extrema". No caso de Ana, enfrentando uma série de situações marcadas por desigualdades articuladas, ela acreditou mover-se de modo a enfrentá-las; a proposta do artigo foi acompanhar sua percepção sobre tais atuações.

Ao compreender agência como um tipo de propriedade dos sujeitos sociais histórica e culturalmente definida, Sherry Ortner (2006b, p. 79) lembra que devemos reconhecer que "a agência é quase sempre distribuída de forma desigual - algumas pessoas conseguem "tê-la", e outras não; algumas pessoas conseguem ter mais, e outras

\footnotetext{
8 Entre 28 trabalhadoras domésticas que participaram da pesquisa, apenas cinco possuíam o ensino médio completo. Entre essas, além de Ana, duas faziam cursos de qualificação profissional. Entre as demais, 6 chegaram ao ensino médio mas não concluíram essa etapa e 17 não ultrapassaram o ensino fundamental (sendo 3 analfabetas).
} 
menos". Nesse sentido, acredito que algumas trajetórias podem ser especialmente frutíferas para atentarmos para o modo - muitas vezes sutil - pelo qual os "atos de agência" operam em contextos marcados por múltiplas desigualdades.

Por meio de perspectiva teórica-metodológica que propõe análises interseccionais sobre gênero, classe e raça, aliada à ênfase nos processos de atuação, argumentei que, na trajetória analisada, a possibilidade de consumo de alguns bens antes acessíveis apenas ao universo das classes média e alta e a qualificação profissional tiveram destaque na busca por agência, conquistas então facilitadas por um contexto socioeconômico favorável, correlato à expansão da "nova classe trabalhadora". Desse modo, o presente artigo buscou trazer, por meio de uma perspectiva antropológica, o olhar para uma trajetória particular, buscando elucidar o modo como marcadores sociais como gênero, cor e classe se inter-relacionam no emprego doméstico no Brasil, ao mesmo tempo em que apontou para a sutileza de algumas possibilidades de agência em tal contexto.

\section{REFERÊNCIAS}

ALMEIDA, Heloisa Buarque. Consumidoras e heroínas: gênero na telenovela. Estudos Feministas, vol. 15, n.1, Florianópolis, jan/2007, p.177-192.

ALMEIDA, Heloisa Buarque. "Classe média" para a indústria cultural. Psicologia USP, vol. 26, n.1, São Paulo, 2015, p.27-36.

AVELINO, Mario. Quadro do emprego doméstico brasileiro. Instituto Doméstica Legal, 09 de jan de 2015. Disponível em: http://www.domesticalegal.org.br/peticao/ Quadro\%20Emprego\%20Dom\%C3\%A9stico\%20Brasileiro.pdf, acesso em 03/ nov/2015.

BARROS, Carla. Trocas, hierarquias e mediação: as dimensões culturais do consumo em um grupo de empregadas domésticas. Tese de Doutorado, Administração, Universidade Federal do Rio de Janeiro, 2007.

BOURDIEU, Pierre. A Distinção: crítica social do julgamento. São Paulo: Edusp, 2007. 
BRAH, Avtar. Diferença, diversidade e diferenciação. Cadernos Pagu. Campinas, n.26, 2006, p. 329-376.

BRANDT, Maria Elisa Almeida. Minha área é a casa de família: o emprego doméstico na cidade de São Paulo. Tese de Doutorado, Sociologia, Universidade de São Paulo, 2003.

BRITES, Jurema. Afeto e desigualdade: gênero, geração e classe entre empregadas domésticas e seus empregadores". Cadernos Pagu, n.29, Campinas, 2007, p.91-109.

BRITES, Jurema. Trabalho doméstico: questões, leituras e políticas. Cadernos de Pesquisa, v.43, n.149, mai-ago/2013, p.422-451.

BRITES, Jurema; PICANÇO, Felícia. O emprego doméstico no Brasil em números, tensões e contradições: alguns achados de pesquisas. Revista Latino-americana de estudos do trabalho, ano 19, n 31, 2014, p. 131-158.

BRUSCHINI, Cristina \& LOMBARDI, Maria Rosa. "A bipolaridade do trabalho feminino no Brasil contemporâneo". Cadernos de Pesquisa, n.110, 2000, pp.67-104.

CRENSHAW, Kimberle. Documento para o encontro de especialistas em aspectos de discriminação racial relativos ao gênero. Revista de Estudos Feministas, vol. 10, n.1, Florianópolis, 2002, p.171-188.

DIEESE. O Emprego doméstico no Brasil. Estudos e Pesquisas, n. 68, ago de 2013. Disponível em http://www.dieese.org.br/estudosetorial/2013/ estPesq68empregoDomestico.pdf, acesso em out/2015.

DOUGLAS, Mary. Pureza e Perigo. São Paulo: Ed. Perspectiva, 1976.

DOUGLAS, Mary; ISHERWOOD, Baron. O mundo dos bens: para uma antropologia do consumo. Rio de Janeiro: Editora UFRJ, 2004.

FIGUEIREDO, Ângela. Cabelo, cabeleira, cabeluda e descabelada: identidade, consumo e manipulação da aparência entre os negros brasileiros. Anais da $26^{\circ}$ Reunião Anual da Associação Nacional de Pós-Graduação e Pesquisa em Ciências Sociais, Caxambu, out/2002.

FREYRE, Gilberto. Casa-grande E Senzala: formação da família brasileira sob o regime da economia patriarcal. São Paulo: Ed. Global, 2006.

HIRATA, Helena. Gênero, classe e raça: interseccionalidade e consubstancialidade das relações sociais. Tempo Social, vol. 26, n.1, São Paulo, jun/2014, p. 61-74.

IPEA, 2011. Situação atual das trabalhadoras domésticas no país. Comunicados do IPEA, N.90. 2011. Brasília, IPEA. Disponível em http://www.ipea.gov.br/portal/ 
images/stories/PDFs/comunicado/110505_comunicadoipea90.pdf, acesso em 11 abr. 2015.

KOFES, Suely. Mulher, mulheres: identidade, diferença e desigualdade na relação entre patroas e empregadas domésticas. Campinas: Editora da Unicamp, 2001.

LIMA, Marcia; REZENDE, Claudia. Linking gender, class and race in Brazil. Social Identities, vol. 10, n. 6, 2004, p. 757-773.

LOPES, Marta; LEAL, Sandra. A feminização persistente na qualificação da enfermagem brasileira. Cadernos Pagu, vol. 24, Campinas, 2005, p.105-125.

MACEDO, Renata Mourão. Espelho mágico: empregadas domésticas, consumo e mídia. Dissertação de Mestrado, Antropologia, Universidade de São Paulo, 2013.

MACEDO, Renata Mourão. Trabalhadoras e consumidoras: transformações do emprego doméstico na sociedade brasileira. Revista Política \& Trabalho, n.42, jan/2015, p.311-333.

MCCLINTOCK, Anne. Couro Imperial: raça, gênero e sexualidade no embate colonial. Campinas: Editora da Unicamp, 2010.

MELO, Hildete Pereira de. O serviço doméstico remunerado no Brasil: de criadas a trabalhadoras. Rio de Janeiro: IPEA (Texto para discussão N. 565), 1998. Disponível em http://ipea.gov.br/agencia/images/stories/PDFs/TDs/td_0565.pdf, acesso em 10 mar. 2013.

MOUTINHO, Laura. Diferenças e desigualdades negociadas: raça, sexualidade e gênero em produções acadêmicas recentes. Cadernos Pagu, n.42, Campinas, 2014, p.201-248.

ORTNER, Sherry. "Uma atualização da teoria da prática”. Anais da 25a. Reunião Brasileira de Antropologia - Conferências e diálogos: saber e práticas antropológicas. Goiânia: Ed. Nova Letra, 2006a.

ORTNER, Sherry. "Poder e projetos: reflexões sobre a agência". Anais da 25a. Reunião Brasileira de Antropologia - Conferências e diálogos: saber e práticas antropológicas. Goiânia: Ed. Nova Letra, 2006b.

PISCITELLI, Adriana. Interseccionalidades, categorias de articulação e experiências de migrantes brasileiras. Sociedade e Cultura, vol. 11, n.2, jul/dez 2008, p. 263-274.

SAFFIOTI, Heleieth. Emprego Doméstico e Capitalismo. Petrópolis: Ed. Vozes, 1978.

SCALCO, Lucia; PINHEIRO-MACHADO. Os sentidos do real e do falso: o consumo popular em perspectiva etnográfica. Revista de Antropologia, São Paulo, vol.53, n.1, 2010, p. 321-359. 
SCALON, Celi; SALATA, André. Uma nova classe média no Brasil da última década? O debate a partir da perspectiva sociológica. Revista Sociedade e Estado, vol. 27, n.2, 2012. p. 387-407.

SEADE. A presença feminina no mercado de trabalho em 2014 na Região Metropolitana de São Paulo. Mulher \& Trabalho, São Paulo, mar/2015, disponível em https://www.seade.gov.br/produtos/midia/mulhertrabalho/Mulher_Trabalho_n26_ marco2015.pdf, acesso em 03 nov. 2015.

SINGER, André. Os sentidos do lulismo: reforma gradual e pacto conservador. São Paulo: Companhia das Letras, 2012.

SOUZA, Jessé. Os Batalhadores brasileiros: nova classe média ou nova classe trabalhadora? Belo Horizonte: Ed. UFMG/Humanitas, 2010.

VELHO, Gilberto. Um Antropólogo na cidade. Rio de Janeiro: Zahar, 2013.

VERSIANI, Isabel. "Com crise, sobe número de domésticas". Jornal Folha de São Paulo, 08 de jun de 2015. Disponível em: http://www1.folha.uol.com.br/ mercado/2015/06/1638845-com-crise-sobe-numero-de-domesticas.shtml, acesso em 05 ago. 2015. 